\title{
Fourier Transform Infrared Spectroscopic Characterization of Kaolinite from Assam and Meghalaya, Northeastern India
}

\author{
Bhaskar J. Saikia ${ }^{1}$, Gopalakrishnarao Parthasarathy ${ }^{2}$ \\ ${ }^{1}$ Department of Physics, Dibrugarh University, Dibrugarh, India \& G B Pant Institute of Himalayan \\ Environment \& Development, Almora, India \\ ${ }^{2}$ National Geophysical Research Institute, (Council of Scientific and Industrial Research) \\ Hyderabad, India \\ E-mail: vaskar_r@rediffmail.com \\ Received June 10, 2010; revised July 27, 2010; accepted August 9, 2010
}

\begin{abstract}
This study demonstrates the Fourier transform infrared (FTIR) spectroscopic characterization of natural kaolinite from north-eastern India. The compositional and structural studies were carried out at room temperature by using X-ray fluorescence (XRF), electron microprobe (EPMA) analyses and Fourier transform infrared (FTIR) spectroscopic techniques. The main peaks in the infrared spectra reflected Al-OH, Al-O and Si-O functional groups in the high frequency stretching and low frequency bending modes. Few peaks of infrared spectra inferred to the interference peaks for quartz as associated minerals. The present study demonstrates usefulness of the spectroscopic techniques in determining quality and crystalline nature of kaolinite from the Assam and Meghalaya, northeastern India.
\end{abstract}

Keywords: Kaolinite, Spectroscopic Characterization, FTIR

\section{Introduction}

Kaolinite is an economically important clay mineral that is common in the weathering, diagentic, hydrothermal, and very low grade metamorphic environments. Kaolinite is one of the most abundant aluminosilicate minerals, occurring primarily as a clay sized particles with high surface-area to volume ratios. Hence kaolinite weathering may play an important role in controlling the chemical characteristics such as degree of crystallinity, concentration of impurities, particles size distribution. Despite its economic and geological importance, the spectroscopic characterization is not well documented. Clay is widely utilized for different industrial applications, and as such any of its occurrences is worth proper chemical, mineralogical and technological investigations. Its current market price (about US $\$ 0.04-0.12 / \mathrm{kg}$ ) is considered to be 20 times cheaper than that of activated carbon [1]. In recent years, there has been an increasing interest in utilizing kaolin for its capacity to adsorb not only inorganic but also organic molecules. It showed that kaolinite and some other naturally occurring clay mineral (such as bentonite, smecttite, diatomite and fullers earth) could use as a substitute for activated carbon as an adsorbent due to its availability and low cost, and its good sorption properties [2]. Clays are layered aluminosilicate minerals forming important components of soils and sedimentary rocks. Their layers consist of $\mathrm{TO}_{4}$ tetrahedra $\left(\mathrm{T}=\mathrm{Si}^{4+}, \mathrm{Al}^{3+}\right.$, etc. $)$ and $\mathrm{MO}_{6}$ octahedra $\left(\mathrm{M}=\mathrm{Al}^{3+}, \mathrm{Fe}^{3+}\right.$, etc.). Layers in 1:1 family of clay minerals hold together by hydrogen bonds formed between hydroxyl groups attached to coordinately unsaturated oxygen sites of the $\mathrm{MO}_{6}$ side of each layer and oxygen atoms terminating the opposite $\mathrm{SiO}_{4}$ side of the next layer [3]. A natural clay consists of one or different type of clay minerals together with some impurities. The most common impurities in natural clay are quartz, calcite, feldspar, mica and organic matter while hydrated iron oxide, ferrous carbonate and pyrite are being the minor impurities. The factors that affect most of the physical properties of clay are particle size, shape, cation exchange capacity and the type of impurities present. Clay particle sizes are in the micrometer to nanometer range length scale. The basic structural units in clays consist of the silica sheet formed 
of silica tetrahedra and the octahedral units formed of octahedrally coordinated cations with oxygens or hydroxyls octahedra [3].

A number of works has been carried out on the quantitative clay mineral analysis using infrared spectroscopy. Vibrational spectroscopic investigations yield useful information about hydration characteristics, interlayer cations and moisture content in clays. The structural differences of kaolin can be detected by spectroscopic method. The FTIR spectroscopy applied to clay mineralogy lies in its ability to characterize the functional group and fingerprint region of very small quantities of samples [4]. The studied samples are collected from six clay occurrence locations of Assam and Meghalaya, viz. Sheelveta, Silanijan and Deopani area of Assam and Khasi Hills, Jaintia Hills and East Garo Hills of Meghalaya. This study demonstrates the complementary role of both FTIR and XRF spectroscopy in characterizing the kaolin of Assam and Meghalaya.

\section{Experimental}

The composition of the clays was determined by using Philips X-ray fluorescence (XRF) machine. The samples were powdered in dry conditions using agate mortar and pestle. The chemical composition of the calumetite was also determined by electron probe micro-analyzer (EPMA). Energy Dispersive X-ray (EDAX) measurements were carried out by using scanning electron microscope (JEOL JSM-840 A) in EDAX mode with a filament current of $100 \mu \mathrm{A}$ and an accelerating voltage of $20 \mathrm{kV}$. Five independent measurements were carried out and the average composition of the calumetite sample is presented here. The chemical constituents and LOI at $800^{\circ} \mathrm{C}$ were determined by the Indian standard method [5] and differential thermal analyses. Differential thermal analysis (DTA) and thermo gravimetric studies were performed on powder samples using a Mettler Toledo star System apparatus. The temperature was measured with platinum sensors. Temperature precision and accu- racy are $\pm 0.1^{\circ} \mathrm{C}$. Thermo gravimetric method is used to quantify the percentage of hydroxyl/water content in the sample. The calibration and reproducibility of this apparatus is discussed elsewhere [6]. In X-ray fluorescence method, typical uncertainty involved in oxide analyses was about $0.01 \mathrm{wt} \%$. The clay samples were crushed into fine powder for analysis. The powdered sample was homogenized in spectroscopic grade $\mathrm{KBr}(1: 20)$ in an agate mortar and pressed into $3 \mathrm{~mm}$ pellets with a hand press. We tried to minimize the grinding time to avoid the deformation of the crystal structure, the ion exchange and the water absorption from atmosphere as suggested by [4]. The infrared spectra was acquired using PerkinElmer system 2000 FTIR spectrophotometer, with He-Ne as the reference, at a resolution of $4 \mathrm{~cm}^{-1}$. The spectra were taken in the region $400-4000 \mathrm{~cm}^{-1}$. The room temperature was $28^{\circ} \mathrm{C}$ during the experiment.

\section{Results and Discussion}

The compositional analysis of the clay samples are performed by XRF analysis (Table 1). It is obvious from Table 1, that improvement on the chemical composition of kaolin as result of beneficiation was marginal. The XRF result shows the major constituents of the samples are silica, alumina, which confirms the chemical analysis of clay. The infrared and compositional analyses indicate that the clay samples belong to kaolin.

The loss on ignition (LOI) was determined at $800^{\circ} \mathrm{C}$. The kaolin sample dehroxylate at about $600^{\circ} \mathrm{C}$, with an intense endothermic peak on the DTA trace. The resultant anhydrous phase transforms into mullite and gamma alumina at about $980^{\circ} \mathrm{C}$, with an exothermic peak in the DTA trace. The relatively large difference in the LOI values between the sample-1 (10.32 wt \%) and sample-3 (4.10 wt \%) indicates that greater loss on ignition took place during the calcination step. This is largely due to the giving off of structural hydroxyl water and volatile organic components.

Figure $\mathbf{1}$ is the IR spectrum of six kaolin samples. The

Table 1. Compositions of the studied kaolin samples (in Weight (\%)).

\begin{tabular}{cccccccccc}
\hline Sample & $\mathbf{S i O}_{2}$ & $\mathrm{Al}_{2} \mathbf{O}_{3}$ & $\mathbf{F e}_{2} \mathbf{O}_{3}$ & $\mathbf{T i O}_{2}$ & $\mathbf{C a O}$ & $\mathbf{M g O}$ & $\mathbf{K}_{2} \mathbf{O}$ & $\mathbf{N a}_{2} \mathbf{O}$ & $\mathbf{L O I}$ \\
\hline Sample 1 & 44.71 & 36.34 & 2.03 & 1.01 & 0.37 & -- & 0.07 & 0.01 & 10.32 \\
Sample 2 & 46.81 & 32.59 & 4.18 & -- & 3.04 & 0.71 & -- & -- & 9.47 \\
Sample 3 & 43.79 & 37.37 & 1.94 & 0.38 & 0.77 & 0.89 & 1.11 & 0.02 & 4.10 \\
Sample 4 & 44.66 & 34.04 & 0.95 & 1.23 & 1.56 & -- & -- & -- & 6.51 \\
Sample 5 & 42.96 & 33.71 & 1.17 & 1.45 & 1.25 & 0.36 & -- & -- & 4.54 \\
Sample 6 & 45.58 & 36.33 & 1.97 & 0.18 & 0.49 & -- & 0.02 & -- & 7.11 \\
\hline
\end{tabular}




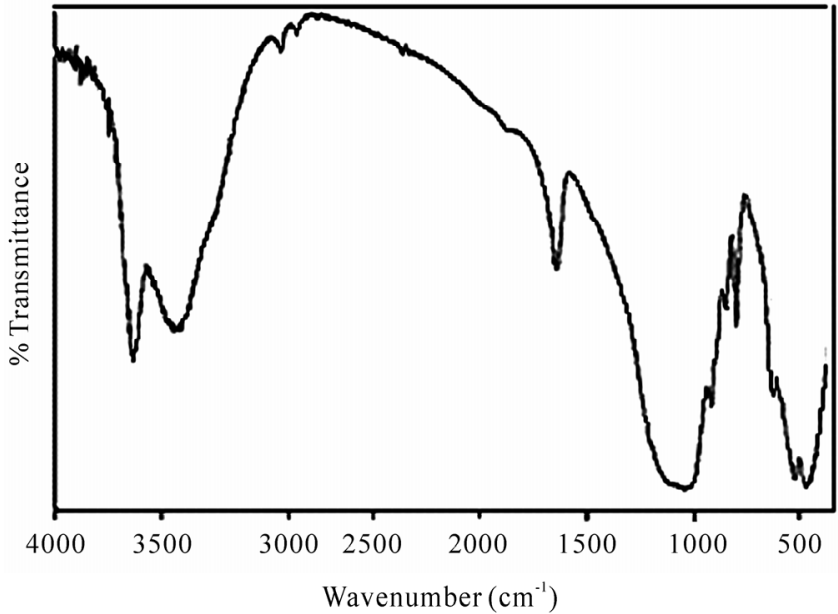

(a)

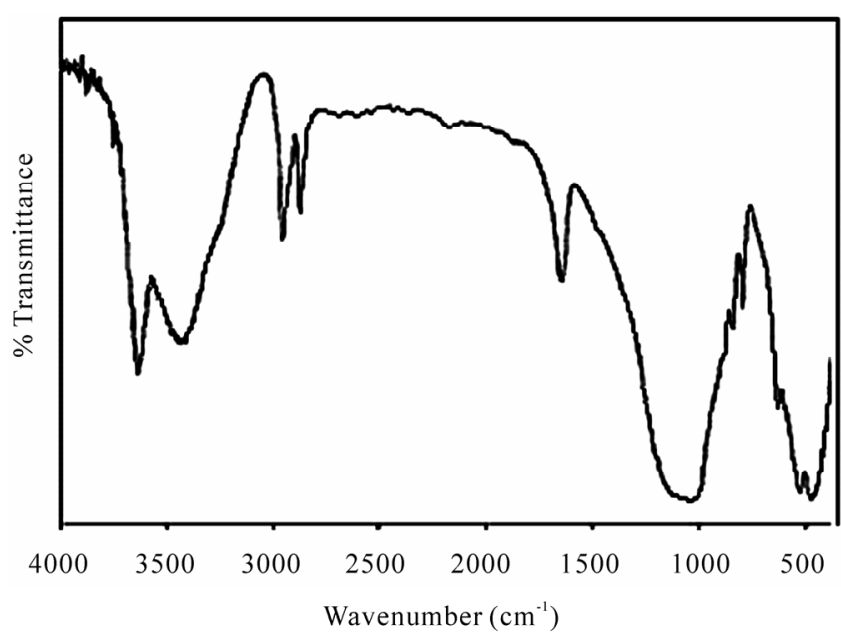

(c)

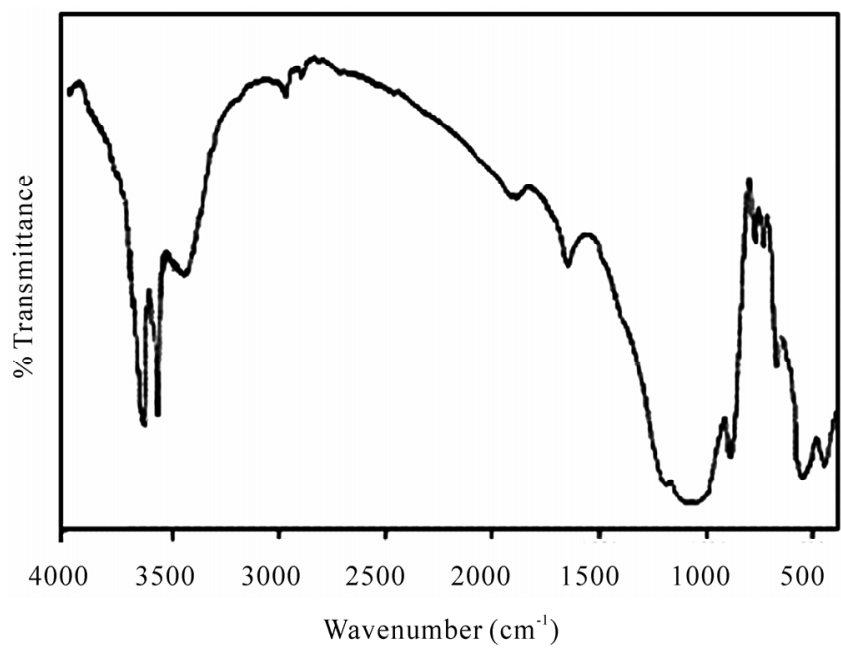

(e)

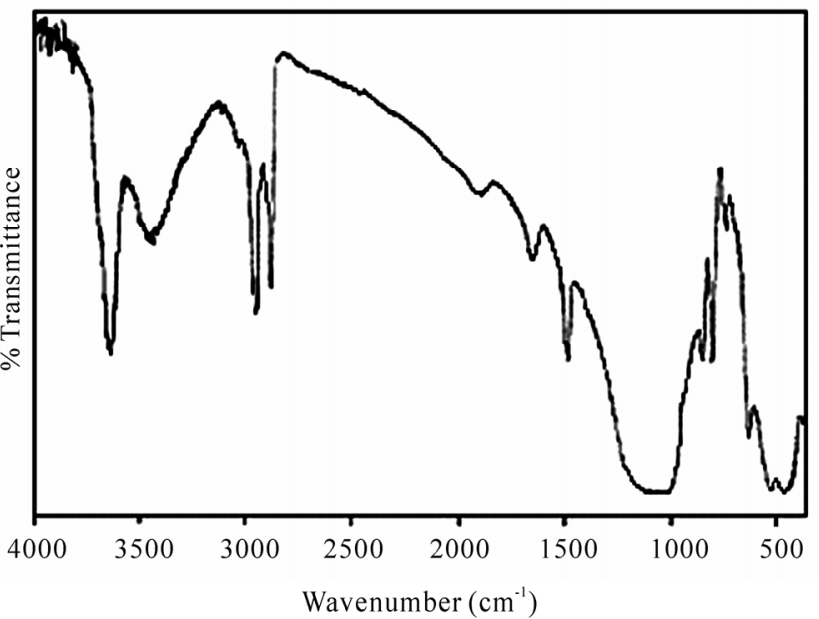

(b)

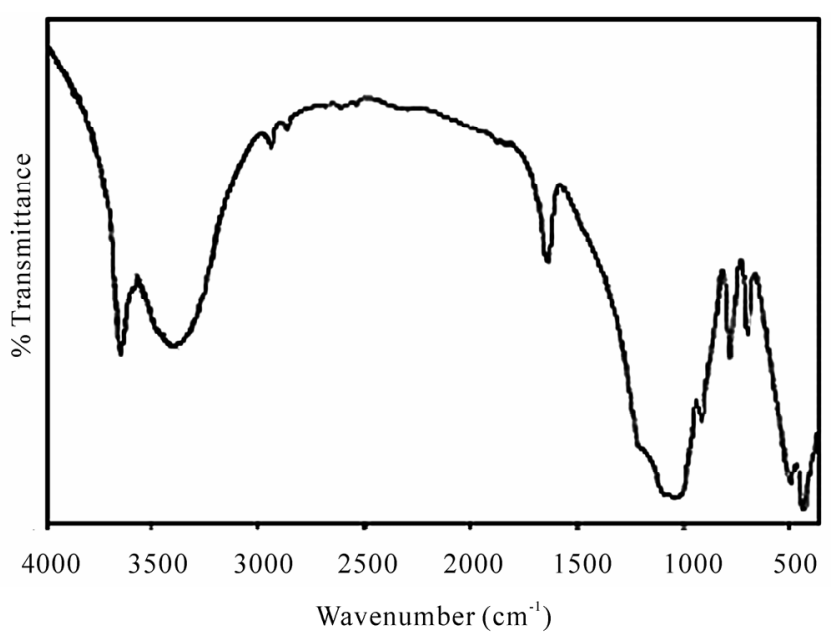

(d)

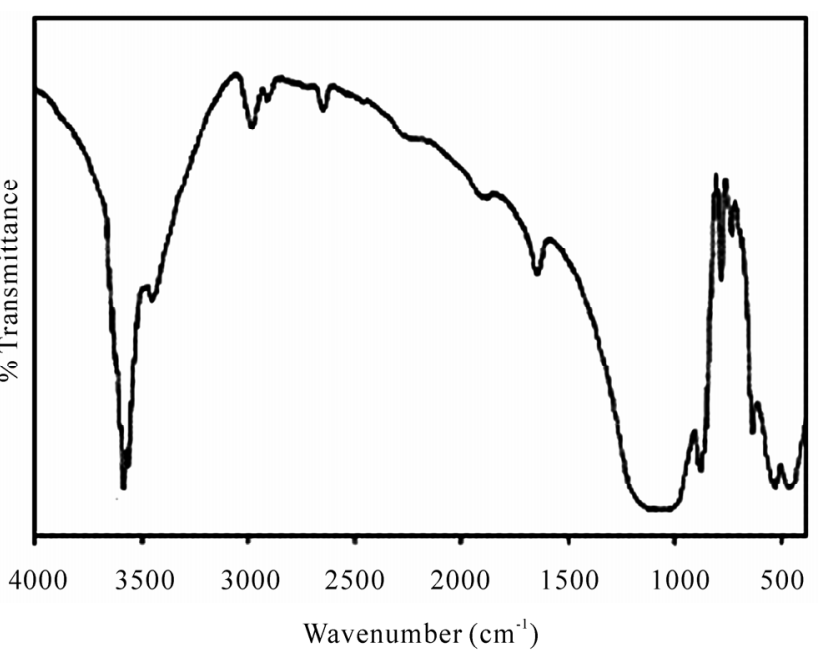

(f)

Figure 1. The infrared spectra of the studied kaolin samples. A: Sample 1, B: Sample 2, C: Sample 3, D: Sample 4, E: Sample 5, F: Sample 6. 
FT-IR technique investigates $\mathrm{OH}$ vibrations, whose absorption bands appear at different frequencies depending on the cations directly linked to the hydroxyls. This permits the determination of cation distribution around hydroxyls and thus allows assessing short-range cation ordering. The band position is compared with the Gadsden (1975) [7] and possible assignments of the samples are presented in the Table 2 . The structure of kaolin minerals consist of a sheet of corner-sharing tetrahedra, sharing a plane of oxygens and hydroxyls (inner hydroxyls) with a sheet of edge-sharing octahedral with every third site vacant (dioctahedral). The general features of the $\mathrm{OH}$ stretching absorption bands are well established for kaolin [8]. A typical spectrum of kaolin show four bands, at $3697,3669,3645$ and $3620 \mathrm{~cm}^{-1}$, and these characteristic bands are observed in the studied kaolin samples as mentioned in the Table 2 . The band observed at around 3620 $\mathrm{cm}^{-1}$ has been ascribed to the inner hydroxyls, and the bands observed at around the other three characteristic bands are generally ascribed to vibrations of the external hydroxyls. The studied kaolin sample exhibits the bands near the three characteristic bands at 3669, 3645 and $3620 \mathrm{~cm}^{-1}$. The absorption bands observed at 3420-3445 $\mathrm{cm}^{-1}$ and $1620-2642 \mathrm{~cm}^{-1}$ could be assigned to the $\mathrm{OH}$

Table 2. Infrared band positions of the studied kaolin samples.

\begin{tabular}{|c|c|c|c|c|c|c|c|}
\hline \multicolumn{7}{|c|}{ Wavenumber $\left(\mathrm{cm}^{-1}\right)$} & \multirow{2}{*}{ Assignments } \\
\hline Theoritical Kaoline & Sample 1 & Sample 2 & Sample 3 & Sample 4 & Sample 5 & Sample 6 & \\
\hline $3670-56$ & -- & -- & -- & 3640 & 3661 & -- & Al---O-H stretching \\
\hline 3645 & 3630 & 3630 & 3634 & 3624 & -- & 3597 & $\begin{array}{c}\text { OH Stretching, } \\
\text { Crystalline hydroxyl }\end{array}$ \\
\hline-- & 3420 & 3440 & 3435 & 3445 & 3429 & 3432 & $\begin{array}{l}\text { H-O-H stretching, } \\
\text { Absorbed water }\end{array}$ \\
\hline-- & 2925 & 2958 & 2920 & 2920 & 2926 & 2931 & $\mathrm{C}-\mathrm{H}$ stretching \\
\hline-- & 2850 & 2854 & 2855 & 2855 & 2864 & 2867 & C-H stretching \\
\hline-- & -- & 1875 & -- & -- & 1835 & -- & -- \\
\hline-- & 1620 & 1642 & 1637 & 1634 & 1635 & 1634 & $\mathrm{H}-\mathrm{O}-\mathrm{H}$ bending of water \\
\hline-- & -- & 1520 & -- & -- & -- & -- & aromatic nitrate \\
\hline-- & 1470 & 1475 & -- & -- & -- & -- & C-H stretching \\
\hline-- & -- & -- & 1347 & -- & 1356 & 1360 & $\mathrm{Al}-\mathrm{O}$ as $\mathrm{Si}$ cage $\left(\mathrm{TO}_{4}\right)$ \\
\hline $1117-05$ & -- & 1175 & -- & 1179 & 1175 & -- & -- \\
\hline-- & -- & -- & 1079 & -- & -- & -- & Si-O quartz \\
\hline $1035-30$ & 1038 & -- & 1038 & 1038 & 1031 & 1033 & $\begin{array}{l}\text { Si-O stretching, } \\
\text { Clay minerals }\end{array}$ \\
\hline 1019-05 & -- & 1005 & 1008 & -- & -- & -- & Si-O stretching \\
\hline $918-09$ & 912 & 910 & -- & 915 & 891 & 893 & $\begin{array}{l}\text { OH deformation, } \\
\text { linked to } 2 \mathrm{Al}^{3-}\end{array}$ \\
\hline $800-784$ & 840 & 840 & 847 & -- & -- & -- & $\begin{array}{l}\text { OH deformation, } \\
\text { linked to } \mathrm{Al}^{3-}, \mathrm{Mg}^{2-}\end{array}$ \\
\hline-- & 788 & 779 & 797 & 778 & 777 & 799 & Si-O quartz \\
\hline $700-686$ & 693 & 690 & -- & 694 & 691 & 696 & Si-O quartz \\
\hline-- & -- & 635 & 673 & -- & 635 & 642 & Si-O-Si bending \\
\hline $542-35$ & 544 & 535 & 535 & 527 & 539 & 543 & $\begin{array}{c}\mathrm{Fe}-\mathrm{O}, \mathrm{Fe}_{2} \mathrm{O}_{3} \\
\text { Si-O-Al stretching }\end{array}$ \\
\hline $475-68$ & 470 & 468 & 470 & 467 & 469 & 467 & Si-O-Si bending \\
\hline
\end{tabular}


vibrational mode of the hydroxyl molecule, which is observed in almost all the natural hydrous silicates. The bands between 3450 and $3670 \mathrm{~cm}^{-1}$ are attributed to the $\mathrm{OH}$ stretching mode. In ferric saponite hydroxyl peaks at 3610 and $3400 \mathrm{~cm}^{-1}$ are characteristic $[6,9]$.

The H-O-H bending of water is observed at 1620-1642 $\mathrm{cm}^{-1}$. In the $1000 \mathrm{~cm}^{-1}(10 \mu \mathrm{m})$ and $500 \mathrm{~cm}^{-1}(20 \mu \mathrm{m}) \mathrm{re}-$ gion, main functional groups were $\mathrm{Si}-\mathrm{O}$ and $\mathrm{Al}-\mathrm{OH}$. Muscovite and possibly quartz interference could be observed at 1031-1038 $\mathrm{cm}^{-1}$ for the studied kaolin. The Al-OH absorption peak was identified at $891-915 \mathrm{~cm}^{-1}$ for the studied sample. The band at $914-936 \mathrm{~cm}^{-1}$ corresponding to Al-OH bending vibrations of kaolinite, the doublet at $780-798 \mathrm{~cm}^{-1}$ is due to $\mathrm{Si}-\mathrm{O}-\mathrm{Si}$ inter tetrahedral bridging bonds in $\mathrm{SiO}_{2}$ and $\mathrm{OH}$ deformation band of gibbsite at $1000 \mathrm{~cm}^{-1}$ are finger-prints of the typical vibrational modes which are recognized easily. In the carbonate and $\mathrm{C}-\mathrm{H}$ bending vibration region, the kaolin samples exhibit some weak peaks (Table 2). The band found at $1347-1360 \mathrm{~cm}^{-1}$ arises due to $2 \mathrm{vs}$, overtone of Al-O as $\mathrm{Si}$ cage $\left(\mathrm{TO}_{4}\right)$. The carbonate structure contains isolated $\mathrm{CO}_{3}{ }^{2-}$ group with a doubly degenerate symmetric stretch (v3) at the region 1508-1560 $\mathrm{cm}^{-1}$ [10]. This band is observed in the studied kaolin at $1520 \mathrm{~cm}^{-1}$. Another band found at $1470-1475 \mathrm{~cm}^{-1}$ is arising due to $\mathrm{Na}^{+} \ldots \mathrm{CO}_{3}{ }^{2-}$ vibration [11]. The $\mathrm{OH}$ deformation of water is found in between $1620-2642 \mathrm{~cm}^{-1}$. The kaolin samples exhibits the $\mathrm{C}-\mathrm{H}$ stretching bands in between $2850-2958 \mathrm{~cm}^{-1}$ indicating polyatomic $\mathrm{C}_{\mathrm{n}}-\mathrm{H}-\mathrm{O}$ entitles with $\mathrm{C}$ bonded to two or three $\mathrm{H}$. The strongest $y_{\mathrm{CH}}$ band in between $2920-2931 \mathrm{~cm}^{-1}$ assigned to symmetrical stretch of $\mathrm{C}-\mathrm{H}$ mode of $-\mathrm{CH}_{2}$-group. The bend between $2850-2867 \mathrm{~cm}^{-1}$ is assigned to anti symmetrical stretch of $-\mathrm{CH}_{2}$-group. Another peak is found at $2954 \mathrm{~cm}^{-1}$ in one kaolin sample due to symmetric stretch of $-\mathrm{CH}_{3}$ group.

\section{Conclusions}

The compositional analysis (XRF) exhibits that kaolin of the study area are constituted of alumina and silica in major quantities. The minor and trace oxide compositions are iron, calcium, magnesium and other elements. The presence of quartz and organic matter as minor phases were confirmed by FTIR analysis. The infrared spectra of the kaolin samples exhibits, the Si-O stretching vibrations at around $778 \mathrm{~cm}^{-1}, 695 \mathrm{~cm}^{-1}$ and 468 $\mathrm{cm}^{-1}$ which is indicative of the presence of quartz in the kaolin samples.

\section{Acknowledgements}

We thank Directors, National Geophysical Research Institute (NGRI), Hyderabad, North East Institute of Science and Technology (NEIST), Jorhat and G. B. Pant Institute of Himalayan Environment and Development (GBPIHED), Almora, for their cooperation during this work. We also thank Dr. P. K. Baruah, Gauhati University, Guwahati, for his assistance in the FTIR analysis.

\section{References}

[1] S. Babel and T. A. Kurniawan, "Low Cost Adsorbents for Heavy Metals Uptake from Contaminated Water: A Review," Journal of Hazardous Materials, Vol. 97, No. 1-3, 2003, pp. 219-243.

[2] P. S. Nayak and B. K. Singh, "Instrumental Characterization of Clay by XRF, XRD and FTIR," Bulletin of Materials Science, Vol. 30, No. 3, 2007, pp. 235-240.

[3] L. Benco, D. Tunega, J. Hafner and H. Lischka, "Ab initio Density Functional Theory Applied to the Structure and Proton Dynamics of Clays," Chemistry Physics Letter, Vol. 333, No. 6, 2001, pp. 479-484.

[4] K. H. Tan, "Principles of soil chemistry," Mariel Dekker Inc., New York, USA, 1998.

[5] Indian Standard Methods of Chemical Analysis of Fireclay and Refractory Materials, 1960, IS: 1527.

[6] G. Parthasarathy, "Effect of High-Pressures on the Electrical Resistivity of Natural Zeolites from the Deccan Trap, Mahrashtra, India," Journal of Applied Geophysics Vol. 58, No. 4, pp. 321-329.

[7] J. A. Gadsen, "Infrared Spectra of Minerals and Related Inorganiccompounds," Butterworths, London, 1975.

[8] V. C. Farmer, "The Infrared Spectra of Minerals," Mineralogical Society, Middlesex, UK, 1974.

[9] G. Parthasarathy, A. C. Kunwar and R. Srinivasan, “Occurrence of Moganite-Rich Chalcedony in Deccan Flood Basalts, Killari, Maharashtra, India," European Journal of Mineral, Vol. 13, No. 1, 2001, pp. 127-134.

[10] G. Parthasarathy, T. R. K. Chetty and S. E. Haggerty, "Thermal Stability and Spectroscopic Studies of Zemkorite: A Carbonate from the Venkatampalle Kimberlite of Southern India," American Mineralogist, Vol. 87, No. 10, 2002, pp. 1384-1389.

[11] P. F. McMillan, G. H. Wolf and B. T. e Poe, "Vibrational Properties of Silicate Liquids and Glasses," Chemical Geology, Vol. 96, No. 3-4, 1992, pp. 351-356. 